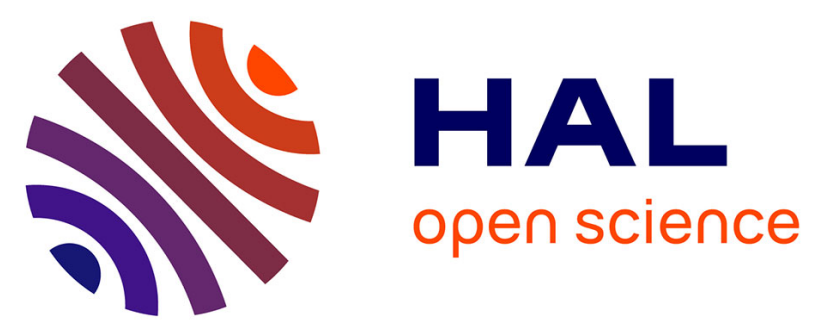

\title{
Trace-based computer supported cooperative work as support for learners group design
}

Marie-Hélène Abel, Ning Wang, Jean-Paul Barthès, Elsa Negre

\section{To cite this version:}

Marie-Hélène Abel, Ning Wang, Jean-Paul Barthès, Elsa Negre. Trace-based computer supported cooperative work as support for learners group design. 21st IEEE International Conference on Computer Supported Cooperative Work in Design (CSCWD 2017), Apr 2017, Wellington, New Zealand. pp.115-120, 10.1109/CSCWD.2017.8066680 . hal-01687880

\section{HAL Id: hal-01687880 \\ https://hal.science/hal-01687880}

Submitted on 5 Jul 2021

HAL is a multi-disciplinary open access archive for the deposit and dissemination of scientific research documents, whether they are published or not. The documents may come from teaching and research institutions in France or abroad, or from public or private research centers.
L'archive ouverte pluridisciplinaire HAL, est destinée au dépôt et à la diffusion de documents scientifiques de niveau recherche, publiés ou non, émanant des établissements d'enseignement et de recherche français ou étrangers, des laboratoires publics ou privés. 


\section{Trace-based computer supported cooperative work as support for learners group design}

\author{
Marie-Hélène Abel, Ning Wang, Jean-Paul Barthès \\ Sorbonne Universités \\ Université de Technologie de Compiègne \\ CNRS UMR 7253 Heudiasyc \\ Compiègne, France \\ Email: \{marie-helene.abel, barthes, ning.wang \}@utc.fr
}

\author{
Elsa Negre \\ Université Paris-Dauphine, CNRS, \\ UMR 7243 Lamsade \\ Paris, France \\ Email: elsa.negre@dauphine.fr
}

\begin{abstract}
Group work, in certain circumstances, could encourage peer learning and provide the learners an opportunity to clarify and refine their knowledge. However, randomly grouping learners of different level of knowledge and activeness could decrease the effectiveness of a group. In this paper, we present a criterion for recommending the formation of groups of learners. This criterion is based on traces collected from interactive digital platforms. Traces are then processed with Bayes Classifier. We implemented this prototype using the MEMORAe approach.
\end{abstract}

\section{INTRODUCTION}

Thanks to web 2.0 technologies working in group is more and more widespread. However, composing a working team is a real problem. The term group composition is used in the sciences of learning and cognition to refer to the characteristics of the group in terms of ability, achievement level, gender, ethnicity, age, etc. In such a context, the composition of a learning group refers to how a group of learners is composed. The learning group can refer to different levels: school, class, group of learners within a class (project group). Each level has its own goal and group composition affects many aspects of its goal achievement, such as how efficiently group members work together and how much relevant knowledge they can share. Thus, when deciding how to compose groups for a project, teacher should : (a) define the project learning objectives, (b) decide how to configure the group (c) identify characteristics of group members relevant to the project learning objectives, (d) select group members, (e) develop a contingency plan in case group membership changes during the project.

In the framework of our work, we are interested in helping the composition of a learning group for a project. We chose to base our approach on learner activity traces in a computer supported collaborative learning. The aim is to propose to the selector of group members, dashboards and recommendations to configure a learner group according some characteristics. This paper is structured as follows. In Section 2 we review the state of the art in the domain of grouping learners, especially e-learning in an online environment. Then, Section 3 presents our proposal including tracing learner activities and the Bayes Classifier we want to apply. In Section 4 we introduce a prototype implementing the approach. Finally in Section 5, we present conclusions and further research plans.

\section{RELATED WORK}

Grouping can be globally divided into homogeneous grouping and heterogeneous grouping ${ }^{1}$. The difference between homogeneous and heterogeneous grouping consist in creating a group of learners presenting or not a similar level of characteristics. These characteristics may be educational levels, ages, cultures, etc. Heterogeneous grouping is used to create a place where each learner can enrich his/her learning from the differences presented by others. On the other hand, usually, homogeneous grouping can generate competition ${ }^{2}$.

In the field of e-learning, research has led to the development of computer-based tools that support automatic group formation. According to their learning needs or individual characteristics, learners are dynamically assigned to groups [1]. They can also be matched to peer learners for a specific task upon request [2], [3], [4]. In [5] several computer-supported grouping techniques are designed and tested. Thinking style scores of students are tabulated from a questionnaire, and are treated as a single point along three orthogonal vectors of thinking styles. In the DIANA system [6], the instructor can perform homogeneous grouping by selecting multiple criteria (up to seven). The Omado Genesis tool [7] introduces an instructor and allows to (a) select the set of learners to apply the grouping; (b) select the grouping type (homogeneous or heterogeneous) for each criteria used; and (c) edit/reform the created groups. Abrami [8] and Cohen [9] have examined how group composing characteristics such as gender, ethnic status, social economic status, and personality type affect learning performance and cooperative interaction.

Most of the works mentioned above group learners based on characteristics or criteria for which they have scores coming from questionnaires, assessments, etc. In the context of computer-based learning environment, by the time learners interact, their activity traces can be used to indicate their activeness and levels of cognition. Our proposal intends to analyze learners previous activities to propose a grouping criterion.

\footnotetext{
${ }^{1}$ Difference Between Heterogeneous And Homogeneous Grouping, http://resumes-for-teachers.com/blog/interview-questions/difference-betweenheterogeneous-and-homogeneous-grouping/, 2016

${ }^{2} \mathrm{http}: / / \mathrm{www}$.cahiers-pedagogiques.com/L-homogeneite-du-groupe-classeun-reve-absurde-et-dangereux, 2017
} 


\section{PRELIMINARIES}

In this section, we first clarify notions such as activity and trace. Then a semantic modeling approach, MEMORAe, is presented. Finally we present the mathematical method, Bayes Classifier.

\section{A. Activity and Trace}

Learners exchange and get new knowledge by realizing activities together. These activities leave traces. Indeed, a digital trace not only contains the values from the environment properties but also the result of a systematic recording of learners interactions with the environment.

Information may be intentionally or unintentionally left behind by the learners. It can then be collected either passively or actively by other interested parties. Depending on the amount of information left behind, other parties can gather large amounts of individual information using simple search engines. Social networking systems may record activities of individuals, with data becoming a life stream. Such a use of social media and roaming services allows digital tracing of data to include individual interests, social groups, behaviors, or location

In a web-based Collaborative Working Environment (CWE), interactions facilitate information sharing. Recording the interactions could constitute an interaction trace. Clauzel et al. [10] defined such a trace as histories of users actions collected in real time from their interaction with the software. It could be used to identify learners working experience (Laflaquière [11]). Thus, once recorded, traces can be considered as a type of resources in the information system. It could specify interactions users have with the software but also interactions users have with other users by means of the software. We group learners based assuming that they have access to a web-based CWE, and that their previous traces can be properly collected.

\section{B. MEMORAe Approach}

In this section we introduce the MEMORAe approach. This approach organizes concepts in a web-based collaborative working environment. The implementation is based on this approach.

The MEMORAe approach is a combination of a semantic model and a web platform sharing the same name to manage heterogeneous resources of knowledge in an organization. A semantic model is a conceptual data model in which semantic information is included. This means that the model describes the meaning of its instances. Such a semantic data model is an abstraction that defines how the stored symbols (the instance data) relate to the real world.

Within MEMORAe approach, MEMORAe-core 2 (mc2) is a semantic model built using OWL (Ontology Web Language) and based on semantic web standards $\left(\mathrm{FOAF}^{3}, \mathrm{SIOC}^{4}, \mathrm{BIBO}^{5}\right.$, etc.). Regarding the typology of ontologies, MEMORAecore 2 contains a core ontology representing collaboration in

\footnotetext{
${ }^{3}$ http://xmlns.com/foaf/spec/

${ }^{4}$ http://rdfs.org/sioc/spec/

${ }^{5} \mathrm{http}: / /$ bibliontology.com/
}

organizations (cf. Figure 1). The model focuses on modeling resource sharing and indexing between individuals and groups of individuals within an organization [12]. The concept mc2:IndexKey (Figure 1) allows to make visible (relation mc2:isVisibleFor) a resource (mc2:Ressource) in a specific work space (mc2:Space) indexed by any concept (owl:Thing) defined in the model. In the case of a course, all the concepts to learn will be defined in a dedicated ontology and will be used as index to access to all resources adapted to its learning by members of a group associated to this work space.

In order to include activities in our model, we chose to import the dedicated web standard PROV Ontology (PROV-O $)^{6}$. by means of specification of activity: mc2:InteractionActivity. PROV-O expresses the PROV Data Model (PROV-DM) using the OWL2 Web Ontology Language. It provides a set of classes, properties, and restrictions that can be used to represent and exchange provenance information generated in different systems and under different contexts. Provenance is information about entities, activities, and people involved in producing a piece of data or thing, which can be used to form assessments about its quality, reliability or trustworthiness.

PROV-DM is the conceptual data model that forms a basis for the $\mathrm{W} 3 \mathrm{C}$ provenance (PROV) family of specifications. PROV-DM is organized in three components, respectively dealing with: (1) entities; (2) activities, and the time at which they were created, used, or ended; and (3) agents bearing responsibility for entities that were generated and activities that happened. Each component is defined as follows:

- Entity: In PROV, things we want to describe the provenance of are called entities and have some fixed aspects. For each concept that could be instantiated from the PROV module, a concept is created as a specialization

mc2: Resource rdfs:subClassOf PROV:Entity

- Activity: In PROV, an activity is something that occurs over a period of time and acts upon or with entities; it may include consuming, processing, transforming, modifying, relocating, using, or generating entities. Just as entities cover a broad range of notions, activities can cover a broad range of notions: information processing activities may for example move, copy, or duplicate digital entities; physical activities can include driving a car between two locations or printing a book. We define digital activities as mc2: InteractionActivity and physical activities in real life as mc2: ProceduralActivity.

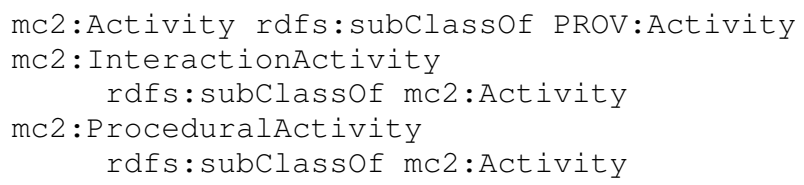

Activities and entities are associated in two different ways: activities utilize entities and activities produce entities. The act of utilizing or producing an entity may have duration. The term generation refers to the completion of the act of producing; likewise, the term usage is the beginning of utilizing an entity by an activity. We import the following object property:

\footnotetext{
${ }^{6}$ PROV-O: The PROV Ontology, https://www.w3.org/TR/2013/ REC-provo-20130430/, 2016
} 


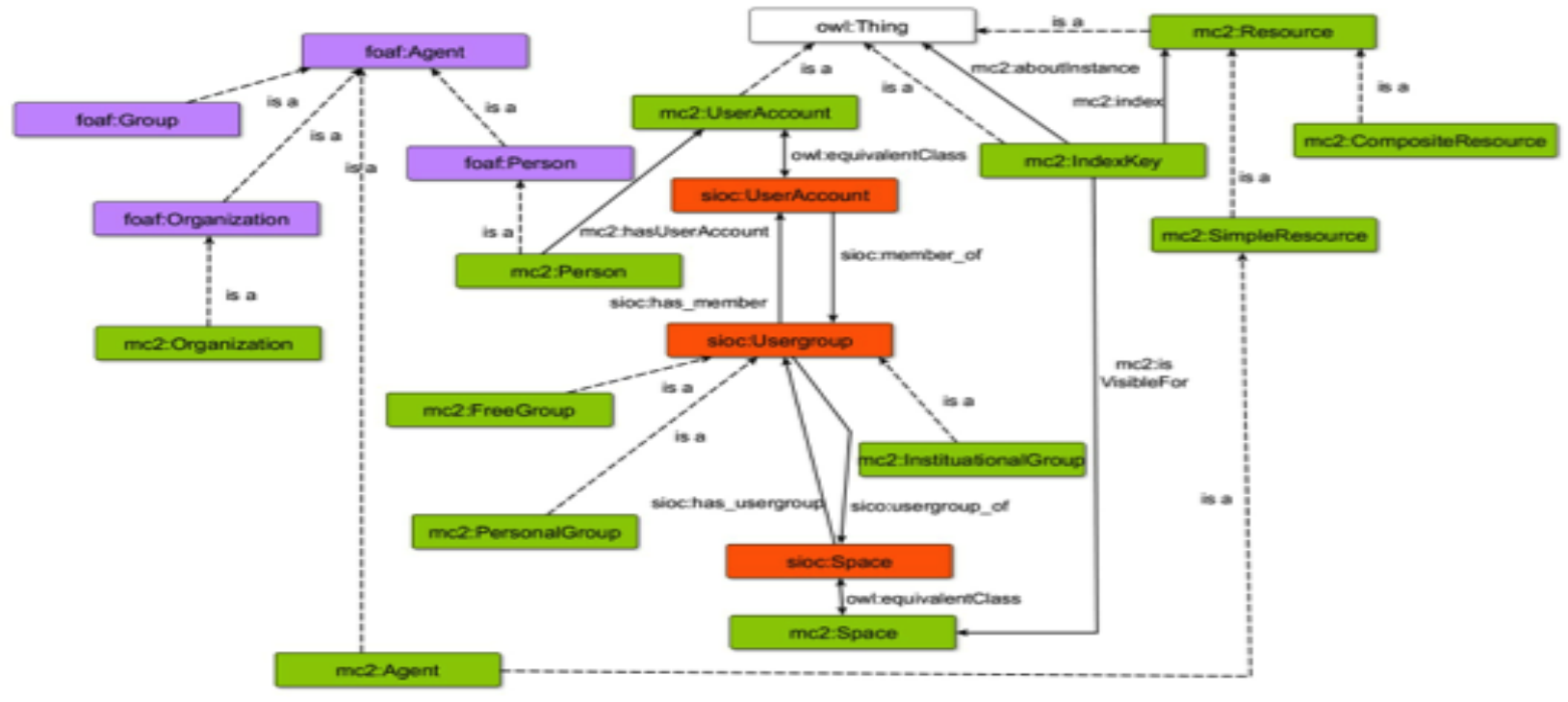

Fig. 1. MEMORAe-core 2 with its modules (partial).

mc2: Activity PROV:used mc2:Resource
mc2: Resource
PROV: wasGeneratedBy mc2: Activity

The PROV:Activity has the following data properties:

PROV:Activity PROV:startedAtTime xsd:dateTime

PROV:Activity PROV:endedAtTime xsd: dateTime

Some activities are marked by two properties. When you get access to a document, the activity is marked by a start time and an end time. Meanwhile, most activities are instantaneous, i.e., they start and end at approximately the same time. For instance, the activity of sharing a document only lasts between the time point that you make a request to the server and the time that the server responds with a success. The duration does not help our analysis. As a preliminary simplification, we suppose that all activities are instantaneous and we import only the data property:

$$
\begin{aligned}
& \text { PROV: } \text { Activity PROV:startedAtTime } \\
& \text { xsd: dateTime }
\end{aligned}
$$

- Agent is something that bears some form of responsibility for an activity taking place, for the existence of an entity, or for another agents activity. An agent may be a particular type of entity or activity. It means that the model can be used to express provenance of the agents themselves. Agents are defined as having some kind of responsibility for activities. The object property PROV: was Associated With is an assignment of responsibility to an agent for an activity, indicating that the agent had a role in the activity:

mc2: UserAccount rdfs:subclassOf
PROV:Agent
mc2:Activity PROV: wasAssociatedWith
mc2: UserAccount (BY INFERENCE)

The specifications of $\mathrm{mc} 2$ : InteractionActivity are as follows:

- CreateActivity: The activity of creating an original resource in the platform, e.g., creating a note;
- DeleteActivity: The activity of deleting a resource in the platform;

- ModifyActivity: The activity of modifying a resource in the platform;

- AccessActivity: The activity of accessing a resource in the platform;

- AddActivity: The activity of adding a resource in the platform which does not exist before, but is not created originally by the user who adds it;

- ShareActivity: The activity of sharing a resource in the platform, e.g., sharing with another group a document which is already added to the platform.

\section{Bayes Classifier}

As a trace is composed of activities on a set of concepts, we need a method that better handles multi-dimensional factors. The Naive Bayes classifier is based on Bayes theorem with a strong (Naive) independence assumption, and is suitable for cases having high input dimensions [13]. In statistical classification the Bayes classifier minimizes the probability of misclassification. In the following, we elaborate on adapting the method to our purpose.

Naive Bayes is a conditional probability model. Given a problem instance to be classified, represented by a vector of features $F=\left(F_{1}, \ldots, F_{n}\right)$, we tend to calculate the probability that it belongs to class Cls. Using Bayes' classic theorem, we have:

$$
p\left(C l s \mid F_{1}, \ldots, F_{n}\right)=\frac{p(C l s) p\left(F_{1}, \ldots, F_{n} \mid C l s\right)}{p\left(F_{1}, \ldots, F_{n}\right)}
$$

To simplify, we use the naive Bayes classifier so that features $F_{1}, \ldots, F_{n}$ are independent. Here we still adapt the classic bag-of-words theory proposed by Mooney and Roy [14] and regard a trace as an independent bag of activities, neglecting 


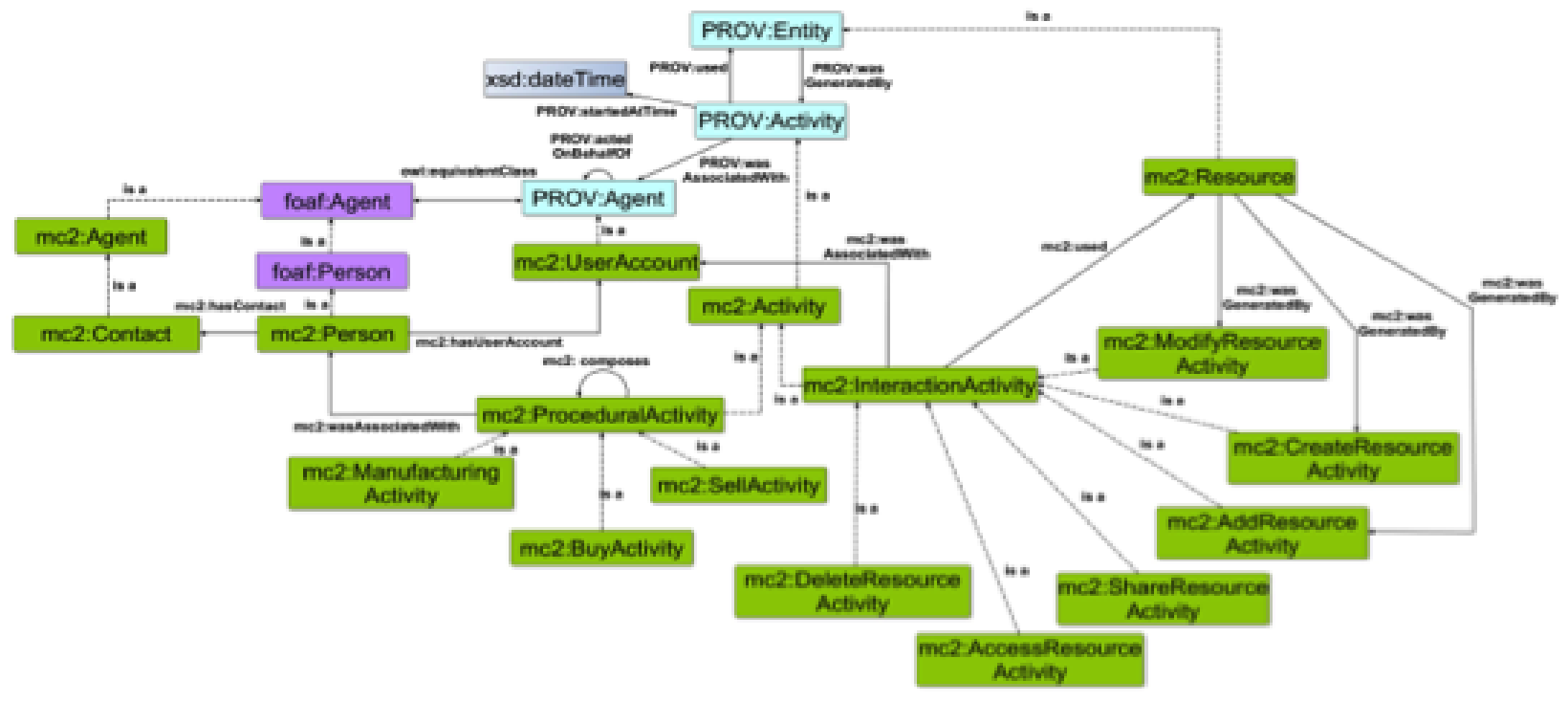

Fig. 2. Integrating the activity module to MEMORAe-CRS ontology.

the logical relationship among the activities. Based on this assumption we have:

$$
\begin{gathered}
p\left(F_{1}, \ldots, F_{n} \mid C l s\right)=p\left(F_{1} \mid C l s\right) p\left(F_{2} \mid C l s\right), \ldots, p\left(F_{n} \mid C l s\right) \\
p\left(F_{1}, \ldots, F_{n}\right)=p\left(F_{1}\right) p\left(F_{2}\right), \ldots, p\left(F_{n}\right)
\end{gathered}
$$

thus Equation 1 is reformulated as:

$$
p\left(C l s \mid F_{1}, \ldots, F_{n}\right)=\frac{p(C l s) p\left(F_{1}, \ldots, F_{n} \mid C l s\right)}{p\left(F_{1}\right) p\left(F_{2}\right), \ldots, p\left(F_{n}\right)}
$$

\section{A CRITERION BASED ON TRACE FOR GROUPING LEARNERS}

In our case, we aim at evaluating a user's competency on a certain concept with a trace he/she left on a set of concepts. So we adapt Equation 1 as:

$$
p\left(\text { Act }_{j} \mid \operatorname{Tra}_{i}\right)=\frac{p\left(\text { Act }_{j}\right) p\left(\operatorname{Tra}_{i} \mid A c t_{j}\right)}{p\left(\operatorname{Tra}_{i}\right)}
$$

where $p\left(A c t_{j}\right)$ is defined as the a priori probability that a random user has the highest competency on concept $j \in$ J. $p\left(A c t_{j} \mid \operatorname{Tra}_{i}\right)$ represents the probability that a user $i \in I$ with trace $\mathrm{Tra}_{i}$ in the platform has the highest competency on concept $j . p\left(T r a_{i}\right)$ is the probability of composing $\operatorname{Tr} a_{i}$. As described previously, a trace is a combination of activities on a variety of concepts. We define $p\left(\operatorname{Tra}_{i}\right)$ as:

$$
p\left(\operatorname{Tra}_{i}\right)=p\left(A_{i, 1}\right) p\left(A_{i, 2}\right), \ldots, p\left(A_{i, n}\right)=\prod_{k} p\left(A_{i, k}\right)
$$

where $p\left(A_{i, k}\right)$ represents the probability that activities of trace $i$ on concept $k$ happen. $\operatorname{Tra}_{i}$ is composed of activities on $n$ concepts respectively. So Equation 5 becomes:

$$
p\left(A c t_{j} \mid \operatorname{Tra}_{i}\right)=\frac{p\left(A c t_{j}\right) p\left(\operatorname{Tra}_{i} \mid A c t_{j}\right)}{\prod_{k} p\left(A_{i, k}\right)}
$$

$p\left(A c t_{j}\right)$ is a constant because with no other conditions, all users have the same probability to perform the best for a concept. With no prior information, the probability of being the most competent among $|I|$ users equals to randomly drawing lot from $N$ users. Thus an estimation of $p\left(A c t_{j}\right)$ is:

$$
\hat{p}\left(\text { Act }_{j}\right)=\frac{1}{|I|}
$$

In our proposition, user competency is measured by the weighted frequency of activities. We use $p\left(A_{i, k}\right)$ as rank of weighted frequency from the top among all users. The more the user $i$ probably acts on concept $k$, the smaller $p\left(A_{i, k}\right)$ is. For example, John realizes activities on concept Java of which the weighted frequency ranks second out of 10 users, then $p\left(A_{\text {John,Java }}\right)=2 / 10=0.2$. It can be explained that if we randomly choose a user $i$ from this set of users, the probability that $i$ performed as much as John on Java is 0.2 .

$p\left(\operatorname{Tra}_{i} \mid A c t_{j}\right)$ represents the probability that user $i$ has a trace $\operatorname{Tr} a_{i}$ if user $i$ has the most competency on concept $j$. Two factors influence this value. Firstly, knowledge and skills are indexed by semantic concepts. If two domains of knowledge are semantically close to each other, it is certain that they have close inner link. Thus if a user has the most competency on $j$, it is highly probable that user $i$ has much competency on semantically related concepts. As $\operatorname{Tr}_{i}$ is composed of a set of activities $\left\{A_{i, k} \mid A_{i, k} \in T r a_{i}\right\}$, we evaluate the semantic distance between $j$ and each $k$. We use $\omega_{k, j}$ to represent the weight of concept $k$ on $j$. Figure 3 shows a part of ontology of a use case for developing a semantic website. In view of complexity of calculations, we consider only the concepts semantically 2 edges away from $j$. Suppose $j$ is the concept "Ontologic_request." Obviously, "Language" and "SQL" are two edges from $j$ and we put their weight of influence to $j$ as $\omega$. "Request" and "SPARQL" are given $2 \omega$ and finally for the concept $j$ itself we allocate $4 \omega$. The sum of weights of concepts is $10 \omega=1$. Secondly, given the weight between concept $k$ and $j$, the higher user $i$ ranks on concept $k$, the bigger $p\left(\operatorname{Tra}_{i} \mid A c t_{j}\right)$ is. 


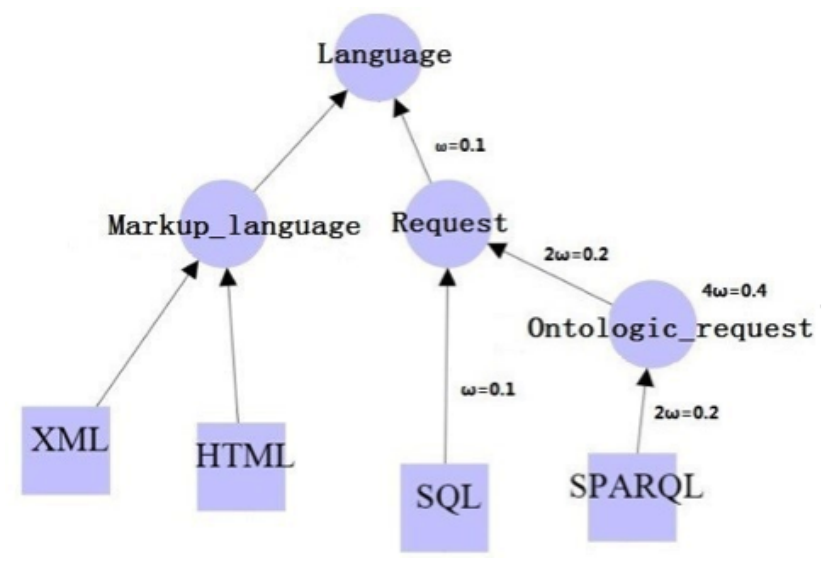

Fig. 3. A part of ontology of a use case for developing a semantic website.

We define:

$$
p\left(\operatorname{Tra}_{i} \mid A c t_{j}\right)=\frac{1}{Z} \sum_{\left\{k \mid A_{i, k} \in \operatorname{Tra}_{i}\right\}}\left[1-p\left(A_{i, k}\right)\right] \times \omega_{k, j}
$$

in which $Z$ is a scaling normalizing factor depending only on $\left\{A_{i, k} \mid A_{i, k} \in T r a_{i}\right\}$, that is, a constant if the values of the feature variables are known. We get:

$$
p\left(\text { Act }_{j} \mid \operatorname{Tra}_{i}\right)=\frac{\sum_{\left\{k \mid A_{i, k} \in \operatorname{Tra}_{i}\right\}}\left[1-p\left(A_{i, k}\right)\right] \times \omega_{k, j}}{N \times Z \times \prod_{k=1}^{n} p\left(A_{i, k}\right)}
$$

Finally, we obtain $p\left(A c t_{j} \mid \operatorname{Tr} a_{i}\right)$ and by comparing the probability of all users on the concept, we can finally give a recommendation about who is most probably the "best" at a concept given his/her trace.

\section{RECOMMENDING LEARNERS}

According to our criterion, it is possible to compare the probability of all learners on a given concept. Thus, we propose to group learners by their activeness on a concept (This activeness is determined by the frequency of activities for a given concept and for related concepts and, the relatedness of concepts is determined by their distance in the ontological model). In fact, based on our criterion, we know which learner is most probably the most active at this concept given his/her trace and then, our approach can recommend to teacher/organizer what kind of learner group to obtain heterogeneous or homogeneous groups of learners. Figure 4 displays our approach for recommending learners to form groups where, from the traces of learners on a collaborative working environment (CWE), a (heterogeneous or homogeneous) group of learners obtained via our criterion is recommended to a teacher/organizer who needs learners group.

\section{PROTOTYPE}

E-MEMORAe web platform is part of MEMORAe approach developed using web 2.0 technologies. It aims at facilitating knowledge sharing and capitalization (Figure 5). E-MEMORAe web platform supports sharing the resources modeled in the semantic model presented in Section III-B. All these resources are indexed by the concepts of an ontology

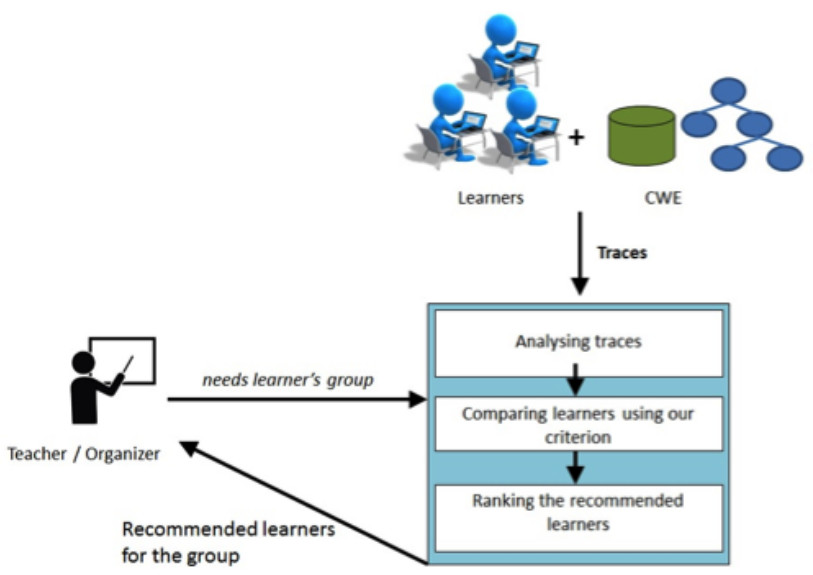

Fig. 4. Recommending learners.

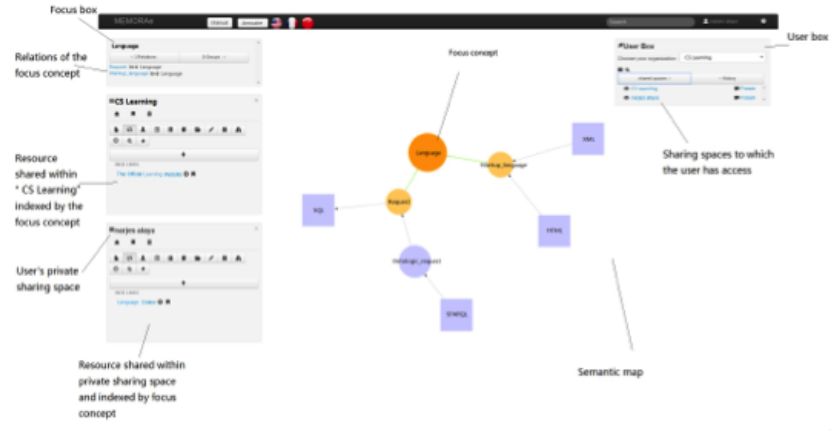

Fig. 5. E-MEMORAe web platform.

that represents the application ontology of an organization. This ontology is presented as a semantic map in the middle of the web page. Initially, users are organized in different groups simply based on the relationship of colleagues. Each group has its own sharing space which only group members have access to. A user can navigate through the map to view shared resources in the sharing spaces.

The platform user can read the recommender results from the sharing space (Figure 7). In this scenario, a list of learners is shown in a descending order of probability of activeness. Each of the users on the list has a probability of most active on the focused concept Markup language. This probability is calculated by Bayes Classifier presented in Section III-C. It is clear that Narjes Alaya and Marie-Hlne Abel have similar probability of activeness on Markup language in this group CS Learning while that of Osama Annabi is much lower.

Furthermore, clicking on each learners name on the recommended list shows by highlight the trace of this recommended learner in comparison to the other learners (Figure 6). This function gives learners a preliminary comprehension of the recommender results.

\section{CONCLUSion AND Future Work}

In this paper we proposed a criterion for grouping learners for either an homogeneous group or an heterogeneous group. To reach this goal, we first adapted the MEMORAe approach to model activities of learners from a web-based collaborative 


\section{Table Review Trace of cs Learning on Markup_language}

\begin{tabular}{|c|c|c|c|c|c|c|}
\hline No. & $x=0$ & pate & Tye Action & $\begin{array}{l}\text { True } \\
\text { Penpource }\end{array}$ & Index & Che. \\
\hline I & Isrietertense & $109-07-2016$ & accents & orent & Morkup_1anguage & $\mathrm{N} / \mathrm{A}$ \\
\hline 2 & Tarie Eblone & $69-07-2016$ & access & docueent & Markup_1anguase & 3.00 \\
\hline 3 & Irrie Gine & $109-07-2016$ & accest & note & Markup_languse & $\mathrm{w} / \mathrm{A}$ \\
\hline 4 & Tarietelelone & $69-07-2016$ & asceess & docuent & Markup_1antuase & 3,00 \\
\hline 5 & narjes & $68-27-2016$ & access & feblinis & Marbug_language & $\mathrm{N} / \mathrm{A}$ \\
\hline 8 & narjes & $68-27-2016$ & accense & -oblink & Markue_lantuate & $w / A$ \\
\hline 8 & narjes & $08-27-2016$ & accens & docuenent & Karkue_languare & $N / h$ \\
\hline 8 & har 5ea & $108-27-2016$ & access & peblink & Marke_language & $\mathrm{N} / \mathrm{A}$ \\
\hline 5 & narjes & $08-27-2016$ & accens: & docuenent & Marbuo_lanruare & 3,00 \\
\hline 10 & narjes & $68-27-2016$ & access & docubent & Narbug_languase & 3.00 \\
\hline 11 & Iarie-Fithe & $68-22-2016$ & acces: & docient & Markup_languase & 3.00 \\
\hline 12 & Tarie-eblone & $68-22-2016$ & asceess & Seblink & Markup_1anguase & 1.00 \\
\hline 13 & Tarie Glothe & $08-22-2016$ & ascess & Neblink & Markup__languase & $\mathrm{N} / \mathrm{A}$ \\
\hline 14 & narjess & $08-22-2016$ & accenses & docievent & Markug_lancuase & 3,00 \\
\hline 15 & Tarie Eolone & $68-22-2016$ & access & docueent & Markup_lantuase & 3,00 \\
\hline 16 & Iarie Fine & $68-22-2016$ & acceses & docierent & Markup_languase & $\mathrm{N} / \mathrm{A}$ \\
\hline 19 & harjes & $67-11-2016$ & accens & note & Markog_languase & $N / A$ \\
\hline 18 & mar jes & $06-09-2016$ & access & cont bet & Markug_language & $\mathrm{N} / \mathrm{A}$ \\
\hline 19 & nar 50 & $106-02-2016$ & access & metlink & Markug_lancuate & $\mathrm{N} / \mathrm{A}$ \\
\hline 20 & losomen & $105-04-2016$ & greate & mote & Markup_1anfuase & W/A \\
\hline 21 & loasen & $64-26-2016$ & access & docieent & Markup_languse & $\mathrm{N} / \mathrm{A}$ \\
\hline 22 & lossens & $103-22-2016$ & ascenes & tour & Markoup_1anguage & $\mathrm{N} / \mathrm{A}$ \\
\hline
\end{tabular}

Fig. 6. Detail of the recommended learners trace in comparison with the others.

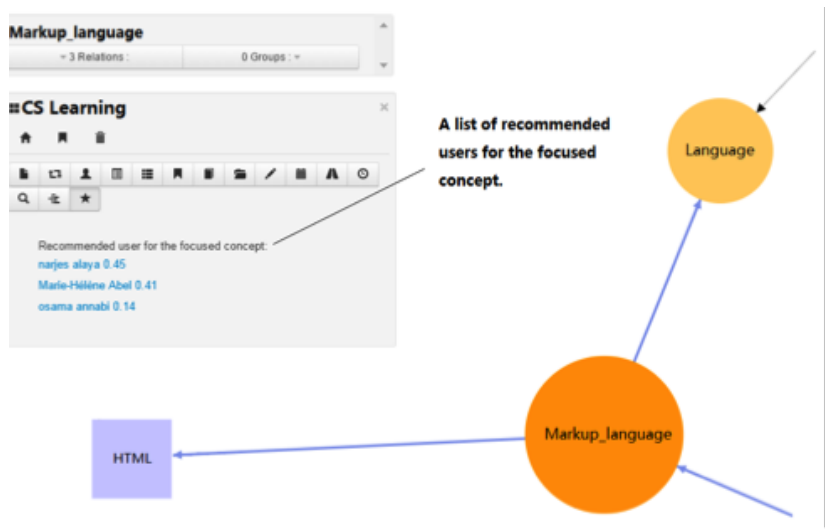

Fig. 7. Results of recommended learners on concept Markup language in the group CS Learning.

environment. Bayes Classifier was applied for analyzing traces and then our approach recommended how to group learners. At last we showed a prototype of learners interacting on the ontology of programming languages. Results of grouping vary based on different needs of the group organizer and thus are not shown in this prototype.

Further work includes (a) improving our system with options of different types of grouping so that the platform can automatically group learners directly; (b) conduct performance analysis (recall, precision, user feedback ).

\section{REFERENCES}

[1] S. Akuma, R. Iqbal, C. Jayne, and F. Doctor, "Comparative analysis of relevance feedback methods based on two user studies," Computers in Human Behavior, vol. 60, pp. 138 - 146, 2016.

[2] J. Greer, G. McCalla, J. Cooke, J. Collins, V. Kumar, A. Bishop, and J. Vassileva, "The intelligent helpdesk: Supporting peer-help in a university course," in Proceedings nternational Conference on Intelligent Tutoring Systems, 1998, pp. 494-503.
[3] A. Inaba, T. Supnithi, M. Ikeda, R. Mizoguchi, and J. Toyoda, "How can we form effective collaborative learning groups?" in Proceedings nternational Conference on Intelligent Tutoring Systems, 2000, pp. 282291.

[4] E. Martin and P. Paredes Barragan, "Using learning styles for dynamic group formation in adaptive collaborative hypermedia systems," in adaptive collaborative hypermedia systems, 2004.

[5] S. Lin and C. Sun, "Team-forming recommendation for web-based cooperative learning: Learning effect and partner preference," in annual meeting of National Association for Research on Science and Teaching, 2000.

[6] D.-Y. Wang, S. S. Lin, and C.-T. Sun, "Diana: A computer- supported heterogeneous grouping system for teachers to conduct successful small learning groups," Computers in Human Behavior, vol. 23, no. 4, pp. 1997-2010, 1994.

[7] A. Gogoulou, E. Gouli, G. Boas, E. Liakou, and M. Grigoriadou, "Forming homogeneous, heterogeneous and mixed groups of learners," in Proceedings ICUM, 2007, pp. 33-40.

[8] P. C. Abrami, Classroom connections: Understanding and using cooperative learning. Harcourt College Pub., 1995.

[9] E. Cohen, "Restructuring the classroom: Conditions for productive small groups. review of educational research," Review of Educational Research, vol. 64, no. 1, pp. 1-35, 1994.

[10] D. Clauzel, K. Sehaba, and Y. Priè, "Modelling and visualising traces for reexivity in synchronous collaborativesystems," in Proceedings of INCOS: Intelligent Networking and Collaborative Systems, 2009, pp. $16-23$.

[11] J. Laflaquière, "Conception de systme base de traces numriques dans les environnements informatiques documentaires," Ph.D. dissertation, UTT, France, 2009.

[12] E. Deparis, "Cration de nouvelles connaissances dcisionnelles pour une organisation via ses ressources sociales et documentaires," Ph.D. dissertation, Universit de Technologie de Compigne, France, 2013.

[13] M. Ghazanfar and A. Prugel-Bennett, "An improved switching hybrid recommender system using naive bayes classifier and collaborative filtering," 2010.

[14] R. J. Mooney and L. Roy, "Content-based book recommending using learning for text categorization," in Proceedings of the fifth ACM conference on Digital libraries, 2000, pp. 195-204. 